\title{
PODE O CONHECIMENTO EM GESTÃO E ORGANIZAÇÃO FALAR PORTUGUÊS?
}

\author{
CAN MANAGEMENT AND ORGANIZATION KNOWLEDGE SPEAK PORTUGUESE?
}

¿PUEDE EL CONOCIMIENTO EN GESTIÓN Y ORGANIZACIÓN HABLAR PORTUGUÉS?

\section{RESUMO}

O objetivo deste artigo é questionar se o conhecimento em gestão e organização (CGO) pode falar um idioma diferente do Inglês e discutir como a hegemonia deste idioma no campo científico tem contribuído para a reprodução da mesma lógica colonial que por séculos impediu os nativos de produzirem sentido acerca do que pensavam, falavam e escreviam. Mostramos que o principal instrumento de poder que garante esta hegemonia é o controle dos crité- rios de publicação e circulação do CGO, que tende a marginalizar tudo o que é produzido fora da base linguística controlada pelo Norte. O principal efeito desta lógica é a submissão dos pesquisadores nativos ao controle do Norte, colocando-os na condição subalterna, condenados em sua própria terra a operar segundo uma lógica externa, que define o que é e o que não é conhecimento científico de qualidade na área de gestão e organização.

PALAVRAS-CHAVE Pós-colonialismo, produção científica, translocalidade, conhecimento científico, língua inglesa.

Alexandre Reis Rosa areis@espm.br

Professor do Departamento de Organizações e Recursos Humanos, Escola Superior de Propaganda e Marketing

São Paulo - SP, Brasil

Mario Aquino Alves mario.alves@fgv.br

Professor da Escola de Administração de Empresas de São Paulo, Fundação Getulio Vargas - São Paulo - SP, Brasil

Abstract This paper's objective is to question whether management and organization knowledge (MOK) is able to speak a language other than English and discuss how the hegemony of this language in the scientific field has contributed to the reproduction of the same colonial logic that for centuries prevented native peoples from making sense of what they thought, spoke and wrote. We show that the main instrument of power that guarantees this hegemony is control over the criteria used for the publication and circulation of MOK, which tends to marginalize everything that is produced outside the linguistic basis controlled by the North. The main effect of this logic is that native researchers submit to control by the North; they find themselves in a subaltern position, condemned in their own country to operate under an external logic that defines what is and what is not quality scientific knowledge in the management and organizational field.

keywords Post-colonialism, scientific production, translocality, scientific knowledge, English language.

Resumen El objetivo de este artículo es cuestionar si el conocimiento en gestión y organización (CGO) se puede hablar un idioma diferente del Inglés y discutir cómo la hegemonía de este idioma en el campo científico hay contribuido para la reproducción de la misma lógica colonial que por siglos impidió los nativos de produjeren sentido acerca de lo que pensaban, hablaban y escribian. Mostramos que el principal instrumento de poder que garantiza esta hegemonía es el control de los criterios de publicación y circulación del CGO, que tiende a marginar todo lo que es producido fuera de la base lingüística controlada por el Norte. El principal efecto de esta lógica es la sumisión de los investigadores nativos al control del Norte, poniéndoles en una condición subalterna, condenados en su propio territorio a operaren según una lógica externa, que es la que define lo que es y lo que no es conocimiento científico de cualidad en el área de gestión y organización.

Palabras clave Postcolonialismo, producción científica, translocalidad, conocimiento cientifico, lengua Inglesa. 
Minha pátria é a língua portuguesa. Nada me pesaria que invadissem ou tomassem Portugal, desde que não me incomodassem pessoalmente.

Fernando Pessoa

Na epígrafe, o poeta português Fernando Pessoa deixa claro que o seu compromisso é com a língua e não com o país. O que o faz se sentir português não é o fato de pertencer a um território politicamente demarcado, mas sim pertencer a uma comunidade linguística capaz de produzir sentido ao que pensamos, falamos e escrevemos. Considerando que a língua portuguesa se espalhou por diversos territórios fora de Portugal, sua capacidade de produzir sentido não depende de um território. Trata-se de um fenômeno translocal que, por meio do colonialismo português, se impôs sobre outras comunidades linguísticas, colocando-se como língua oficial de todas as colônias portuguesas, entre as quais o Brasil (THOMAZ, 2007).

Assim como o colonialismo francês e britânico, que também se estabeleceu sobre as línguas nativas, impondo seus idiomas como línguas oficiais, a coroa portuguesa criou uma base comum de comunicação entre as colônias, facilitando o fluxo de informações, pessoas e mercadorias. Esse fluxo, porém, era assimétrico, ou seja, do Sul para o Norte seguia apenas matéria-prima, do Norte para o Sul seguiam os produtos manufaturados, a literatura, a tecnologia e, no caso do Brasil colonial, em 1808, esse fluxo trouxe um Estado inteiro, com sistema político, jurídico, econômico e cultural (veja FAUSTO, 1995). O domínio português sobre a base linguística que sustentava todas essas estruturas garantia-lhe um sentido de "progresso" e de "desenvolvimento" para a colônia. Como o fluxo se manteve assimétrico por séculos, os povos nativos viram-se impedidos de produzir sentido fora da estrutura de poder colonial, tornando-se um condenado em sua própria terra, um sujeito subalterno fadado a seguir um destino externo, determinado pelo sujeito europeu (FANON, 1965).

Quando analisamos o contexto pós-colonial, observamos os mesmos princípios do colonialismo europeu ainda em funcionamento: (1) a desterritorialização das estruturas políticas, econômicas e linguísticas; (2) um fluxo assimétrico de informações, pessoas e mercadorias entre o Norte e o Sul global; e (3) a impossibilidade de se produzir sentido fora da estru- tura de poder colonial. Dentro desse contexto, ocorre a formação de um campo científico "internacional", comprometido mais com os aspectos translocais da sua produção (APPADURAI, 1996) do que com a dinâmica interna dos seus países, tal qual afirma o poeta Fernando Pessoa. Trata-se de uma comunidade científica internacional, cuja base linguística comum tem sido o idioma inglês - visto como "língua franca" da ciência - e a hierarquia dos grupos estabelecida pela tradicional dicotomia Norte/Sul. Sendo o "Norte" e o "Sul" entendidos aqui como uma metáfora para designar os países do hemisfério Norte, leia-se Europa e Estados Unidos da América (EUA), em contraponto aos países do hemisfério Sul, formado pelo conjunto de países e regiões do mundo que foram submetidos ao colonialismo europeu e que não atingiram níveis de "desenvolvimento" econômico semelhantes aos do Norte (SANTOS, 1995).

O primeiro problema dessa base linguística comum é que ela atende perfeitamente aos interesses dos países do Norte global que controlam o centro da produção de conhecimento científico mundial. No que se refere ao Conhecimento em Gestão e Organização (CGO), os EUA dividem o controle desse centro com o Reino Unido (UK). Assim, todo o conhecimento produzido nesse centro não obedece mais às fronteiras territoriais, assumem um caráter global e se espalham pelo mundo afora como um conhecimento global sobre gestão e organização (BOYACIGILLER, ADLER, 1991).

O segundo problema é que, ao definir o inglês com base linguística comum, excluem-se outras línguas e o fluxo de informações entre o Norte e o Sul começa a operar em apenas um sentido: do Norte para o Sul. Se o circuito global de produção de conhecimento científico opera apenas sob o idioma inglês, então se torna inviável que uma pesquisa feita em outra língua circule nesse circuito (veja MERILÄINEN e outros, 2008). Assim, chegamos ao terceiro problema gerado pelo domínio do idioma inglês: a impossibilidade de o sujeito subalterno falar. Ele fica condenado a não se expressar em sua língua nativa, sendo obrigado a se mover nos limites autorizados pela estrutura de poder controlada pelo Norte Global, isto é, em inglês.

Nosso objetivo neste artigo é questionar se o CGO pode falar idioma diferente do inglês e discutir como a hegemonia desse idioma no campo científico tem contribuído para a reprodução da mesma lógica colonial que por séculos impediu os nativos de produzirem sentido 
acerca do que pensavam, falavam e escreviam. Mostramos que o principal instrumento de poder que garante essa hegemonia é o controle dos critérios de publicação e circulação do CGO, o qual tende a marginalizar tudo o que é produzido fora da base linguística controlada pelo Norte. O principal efeito dessa lógica é a submissão dos pesquisadores do Sul ao controle do Norte, colocandoos na condição subalterna, condenados em sua própria terra a operar segundo uma lógica externa, a qual define o que é e o que não é conhecimento científico de qualidade na área de gestão e organização.

\section{INGLÊS COMO LÍNGUA GLOBAL}

Nas últimas décadas, a pluralidade de idiomas no campo específico da produção científica tem diminuído com a proeminência do inglês, o que tem gerado um modelo assimétrico de relações entre as línguas, criando formas específicas de hierarquia que representam relações de poder diferenciadas no campo da ciência (HAMEL, 2007). Segundo De Swaan (1993), até o fim da Primeira Guerra Mundial, o inglês pertencia a um pequeno grupo de línguas dominantes, chamadas de línguas supercentrais (francês, espanhol, russo, chinês, japonês, árabe, híndi, alemão e português), que dominavam na produção científica mundial. Após a Segunda Guerra Mundial, contudo, o inglês, como língua dominante, assumiu o papel de língua "hipercentral". Com efeito, sua expansão vem tornando todas as demais línguas periféricas, absorvendo suas funções na maioria dos fóruns internacionais. Assim, emerge um novo processo mundial de bilinguismo: todos falam a sua língua nativa e, ao mesmo tempo, adotam o inglês como sua única língua estrangeira (CRYSTAL, 1997).

Esse processo de expansão do inglês pelo mundo tem sido analisado, ao mesmo tempo, como oportunidade e como ameaça (KUSHNER, 2003). A primeira defende a hegemonia do inglês pela sua "funcionalidade" de promover uma base neutra de comunicação, como uma "língua franca" que facilita a comunicação entre os grupos (CRYSTAL, 1997). A segunda, por sua vez, não aceita a suposta neutralidade desse processo. Ao contrário, assume um posicionamento "crítico" sobre a expansão do inglês, encarando-a como uma relação de poder que gera uma série de injustiças, desigualdades e discriminações na medida em que coloca o inglês no "centro" da produção de conhecimento no mundo e empurra todas as outras línguas para a "periferia" dessa produção (PHILIPSON, 1992).

Dentro dessa perspectiva crítica, Ortiz (2004) argu- menta que esse domínio do inglês como "língua franca" das ciências naturais poderia até mesmo funcionar e tornar o intercâmbio de ideias mais equitativo, porém, faz a ressalva de que, no campo das ciências humanas, isso seria impossível, pois a língua é fundamental na construção do objeto social na medida em que se refere ao sentido atrelado às especificidades históricas e geográficas de um dado contexto. Assim, a produção científica deve atender à pluralidade idiomática desses diversos contextos. Quando uma língua predomina, portanto, isso ocorre porque há uma hierarquização de poder no mercado de bens linguísticos, que, como será mostrado mais adiante, reflete uma falsa aproximação entre o particular e o universal. Dessa forma, abre-se uma nova forma de dominação, caracterizada pelo domínio do código linguístico (PEASE, 2005).

Com o domínio do idioma inglês, os pesquisadores do Norte se colocam numa posição privilegiada, já que conseguem controlar toda a produção e o fluxo de informação científica por meio dos canais de distribuição (periódicos) e das agências voltadas para o financiamento de determinados temas de pesquisa (MERILÄINEN e outros, 2008). Assim, se o pesquisador do Sul deseja participar dessas arenas, e, como consequência, ocupar posições de poder no centro do campo científico, deve, necessariamente, abandonar a sua língua nativa e submeter-se à língua hegemônica. Essa submissão dependerá da permeabilidade das culturas nativas às forças exógenas, em particular ao discurso anglófono (ou voz do Norte Global).

\section{GEOPOLÍTICA EPISTÊMICA E A GLOBALIZAÇÃO DO CONHECIMENTO}

O conhecimento sobre Gestão e Organização assume hoje um status global, pois é amplamente disseminado por meio de revistas científicas e de negócios, e também pelos cursos oferecidos para gerentes e estudantes de todo o mundo. Trata-se de uma disciplina global (BOYACIGILLER, ADLER, 1991), cujos conteúdos - produzidos principalmente pelos EUA - são vistos muitas vezes como "universais" e supostamente transferíveis, sem maiores problemas, para outros contextos (FRENKEL, SHENHAV, 2003).

A lógica por detrás desse processo, segundo Mignolo (2002), está atrelada a um contexto mais amplo, em que epistemologias são produzidas a partir de uma linha divisória que hierarquiza os saberes e subordina o que é pensado localmente (visto como particular) ao que é 
pensado globalmente (visto como universal). Essa relação desigual de saber-poder, a qual conduziu à supressão de muitos saberes próprios dos povos colonizados, é denominada "colonialidade do poder" por Quijano (2000) e à forma como essa diferença epistemológica foi (re)produzida, Santos (2007) denomina de "pensamento abissal". Ambos operam no sentido de definir unilateralmente as linhas que dividem experiências, saberes e atores sociais em dois grupos que habitam cada lado do "abismo": de um lado, estão os saberes hegemônicos, úteis, inteligíveis e visíveis produzidos pelo Norte. De outro, os saberes subalternos, inúteis ou perigosos, ininteligíveis e invisíveis produzidos pelo Sul.

Essa configuração tem início com a própria concepção das ideias de modernidade e colonialismo (veja ESCOBAR, 2007; DUSSEL, 1993), que se desenvolveram por meio das seguintes operações epistêmicas: (1) forte ênfase na localização das origens da modernidade nas grandes navegações, que propiciaram a conquista da América e o controle do Atlântico; (2) maior atenção aos fenômenos do colonialismo e da construção do sistemamundo capitalista como constitutivos da modernidade; (3) adoção de uma perspectiva de mundo na explicação da modernidade, em consonância com uma visão da modernidade como um fenômeno intra-europeu; (4) identificação da dominação dos outros povos não europeus como uma dimensão necessária da modernidade, com a consequente subalternização do conhecimento e da cultura desses outros povos; e (5) concepção do eurocentrismo como a forma de conhecimento da modernidade, o que é, simultaneamente, uma representação hegemônica e um modo de saber que advoga a universalidade para si, assentado em uma confusão entre a universalidade abstrata e a hegemonia mundial derivada da posição central ocupada pelos países do Norte.

Angel Rama (1985) mostrou que a cidade colonial desempenhou um papel central na construção de uma epistemologia que demarcava a superioridade entre o conhecimento da metrópole e o conhecimento dos povos indígenas, por meio da introdução da língua europeia e seu intrincado sistema de signos. Assim, coube à "cidade letrada" cumprir sua missão civilizatória a partir do século XVI. Na cidade, sacerdotes criavam, por meio do ensino e da catequização, um universo de signos e símbolos que legitimavam o poder da metrópole. Tradições orais e códigos linguísticos não alfabéticos foram duramente reprimidos pela "cidade letrada". Esse procedimento "civilizatório" se completou com a instituição da "cidade escriturária", lugar onde o convívio próximo ao poder, às leis, aos regulamentos e aos "proclamas" reais criou uma classe de administradores públicos - advogados, juízes, escrivães e escreventes - que realizava a arte da "obscura predominância", pela qual a língua funcionava como o instrumento de dominação e controle contra o "mundo inferior", representado pelos "iletrados" que, por não dominarem ou aderirem à norma culta, tiveram um acesso limitado aos espaços de poder da "cidade" (RAMA, 1985).

Assim, pode-se afirmar que o processo de criação de uma geopolítica epistêmica implica também a formação de uma elite intelectual local que sirva de agente perpetuador do pensamento hegemônico que condena o conhecimento não eurocentrado à condição de subalternidade. Essa elite local é definida pela teoria pós-colonial como "comprador", cuja origem remete à figura do antigo mercador local que atuava como mediador entre os produtores estrangeiros e os consumidores locais. No contexto do eurocentrismo, esse "comprador" assume o papel da intelligentsia local (acadêmicos, escritores e artistas), responsável por traduzir o conhecimento estrangeiro para os grupos autóctones. Por conta dessa habilidade, o "comprador" detém privilégios junto à "cidade letrada", não se engajando nas lutas por independência política e cultural (ASHCROFT, GRIFFITHS, TIFFIN, 2000).

Nesse sentido, Bourdieu e Wacquant (1999) argumentam que a "razão imperialista" se utiliza do recrutamento de intelectuais por meio de bolsas de pesquisa, estágios no exterior e movimentos semelhantes, tudo isso com o intuito de fazer valer a visão eurocêntrica, cujo poder se fundamenta na capacidade de universalizar particularidades associadas a uma tradição histórica singular, tornandoas irreconhecíveis como tais quando aplicadas a outros contextos. A manutenção dessa universalidade é garantida por meio de políticas educacionais (ensino, pesquisa e extensão) baseadas em padrões de qualidade que são definidos pelo Norte - com seus currículos, conteúdos e linguagem - e didaticamente assimilados pelo Sul como modelos de desenvolvimento oficial (TIKLY, 2004). Isso acaba tendo reflexos no campo acadêmico, cuja legitimidade se ancora em "quem são" e "onde estão" os centros de excelência mundial em pesquisa, e também "quais são" os periódicos que publicam e exibem para a comunidade acadêmica mundial a "pesquisa de qualidade".

\section{HEGEMONIA DO IDIOMA INGLÊS NO CGO PRODUZIDO NO BRASIL}

Para March (2004), uma das principais aspirações de uma ciência social é a criação de uma associação de 
pesquisadores multidisciplinar, multinacional e multilingual, que possibilitasse uma rica circulação de ideias através das fronteiras disciplinares, nacionais e linguísticas. Embora ele argumente que isso seja possível a partir de uma visão "funcional" do inglês como "língua franca", o próprio March (2004, p.7) reconhece que isso poderia trazer alguns problemas na medida em que "[...] ela cria um viés em favor da experiência, pesquisadores e visões de mundo anglófonas, uma tendência que tanto contribui para e é reforçada por uma hegemonia norte-americana nos estudos organizacionais".

Esses limites e possibilidades apresentados por March (2004) aparecem também no debate brasileiro sobre a participação do Brasil no circuito científico internacional. Entre os que assumem a funcionalidade do inglês como "língua franca" está, por exemplo, o argumento de Prochno em favor do inglês como língua padrão da ciência, pois seu uso "[...] acaba por democratizar o acesso à informação, diminuindo a necessidade de custosas traduções entre línguas pouco faladas" e, diferente da ressalva feita por March (2004), argumenta também que "se alguém paga um preço, são os acadêmicos dos EUA e outros países de língua inglesa: ao não aprenderem uma nova língua, deixam de ter benefícios que viriam nesse aprendizado. Sorte a nossa que o português não é a língua comum para a comunicação entre diferentes nacionalidades"(PROCHNO, 2008, p. 857).

Em outra linha de argumentação, Goulart e Carvalho negam a suposta neutralidade do idioma inglês, reconhecendo-o como "[...] um instrumento privilegiado de dominação que aporta toda a carga simbólica e ideológica que, mais do que universalizar a troca de conhecimentos, induz o modo de pensar de uma referência histórica, política, geograficamente situada" (GOULART, CARVALHO, 2008, p. 879). Embora tenhamos a ressalva feita por March (2004) sobre os problemas gerados pela predominância do idioma inglês no campo e a observação de Goulart e Carvalho (2004) sobre a interferência disso no modo de pensar a nossa realidade, a flagrante presença do inglês nos estudos brasileiros sobre gestão e organização nos leva a perceber que tem prevalecido uma postura de conformidade a esse processo, tal qual assume Prochno (2008) ao defender o inglês como "língua franca".

Diante disso, nosso argumento é que o controle da produção do conhecimento produzido no campo, através da pesquisa e das publicações, tem sido o principal pilar de manutenção da hegemonia do inglês e também a principal barreira que impede a participação do Sul no campo acadêmico transnacional.

\section{O INGLÊS NA PESQUISA E PUBLICAÇÃO EM GESTÃO E ORGANIZAÇÃO}

Diversas análises sobre a produção científica no campo da gestão e organização atestam sua permeabilidade em relação ao conhecimento produzido no contexto anglo-saxão. O estudo realizado por Bertero e Keinert (1994) sobre as publicações de 1961 a 1993 comprova a hegemonia de autores anglófonos no período analisado. Nessa análise, os autores concluem que a nossa produção tende a repetir didaticamente o que foi produzido lá fora, em especial o que foi produzido nos EUA. Na mesma linha seguem os trabalhos de Vergara (2001) e Vergara e Pinto (2001), que identificam os mesmos padrões no âmbito das citações estrangeiras, cuja autoria se concentra entre autores americanos e britânicos. Outro estudo importante é o de Rodrigues e Carrieri (2001), o qual identifica as mesmas concentrações encontradas nos estudos anteriores. Além disso, os autores fazem um balanço da área e analisam o acesso dela ao circuito internacional. Entre as barreiras listadas, está um modelo de academia fora das expectativas internacionais, com tipos de pesquisa, redação e publicação pouco desenvolvidos quando comparados ao que é feito nos países centrais.

Mesmo que essas barreiras tenham diminuído na última década (pois a análise de Rodrigues e Carrieri foi publicada em 2001), ainda ocupamos uma posição periférica no circuito internacional, o que nos coloca em desvantagem no que diz respeito a nossa representatividade no campo. Diversos estudos sobre nossa produção científica (veja BERTERO, CALDAS e WOOD JR, 2005) confirmam essa limitação, principalmente em relação à qualidade dessa produção. Mas quem define essa qualidade? Qual é o parâmetro utilizado para definir a pesquisa de qualidade? No atual contexto de avaliação científica, o principal mecanismo de mensuração dessa qualidade é o sistema Qualis, instituído em 1998 como componente importante no processo de avaliação da Coordenação de Aperfeiçoamento de Pessoal de Nível Superior - CAPES (LUIZ, 2006).

No campo da Administração, o sistema Qualis estabelecia, até o ano de 2008, sua classificação de pontos a partir de uma escala de dupla entrada relativa ao âmbito de circulação (internacional, nacional e local) e à sua qualidade (A-alta, B-média e C-baixa). Nesse modelo, as publicações mais valorizadas eram aquelas cuja combinação era Internacional-A. Nenhum periódico brasileiro entrava nesse recorte e, dos que entravam, 95\% deles era em língua inglesa e apenas 5\% em 
outras línguas (alemão e francês). A partir do triênio 2007-2009, a CAPES reestruturou o Qualis. Ao contrário da classificação anterior, os periódicos passaram a ser avaliados a partir de uma única classificação com a fusão dos critérios de âmbito e qualidade em oito segmentos: A1, A2, B1, B2, B3, B4, B5 e C. Dessa forma, os periódicos com melhor e pior avaliação são classificados como A1 e B5, respectivamente. Os periódicos não indexados no Qualis recebem a classificação C. Nessa nova classificação, buscou-se a utilização do fator de impacto (FI) como critério de pontuação dos periódicos, o que, na avaliação comparativa feita por Machado-da-Silva e outros (2008), não acarretou mudanças significativas para os periódicos já classificados anteriormente nos melhores segmentos de circulação e qualidade. Conforme mostra o Gráfico 1, a valorização dos periódicos em inglês se manteve estável no segundo modelo.

Na Gráfico 1, observamos que, quanto mais próximo das melhores classificações, há um percentual maior de periódicos em inglês e, quanto mais distante delas, aumenta o número de periódicos em outros idiomas. Assim, entre os periódicos mais valorizados no extrato A1, 97\% deles são editados em língua inglesa e apenas $3 \%$ em outras línguas. Esse pequeno percentual, entretanto, refere-se a dois periódicos na área de Saúde Pública que, embora possuam algumas interfaces com a área de gestão, não são periódicos específicos desse campo de conhecimento. Além disso, apenas um deles é editado somente em português.

No segundo extrato mais valorizado, o A2, aparecem os primeiros periódicos brasileiros específicos do campo de gestão e organização. Trata-se da Revista de Administração Pública (RAP), editada em português, e da Brazilian Administrative Review (BAR), editada somente em inglês. Todos os demais 19 periódicos brasileiros que aparecem neste extrato são de outras áreas de conhecimento (Engenharia, Psicologia, Sociologia, Agronomia etc.). O número de periódicos específicos da área de gestão e organização começa a se tornar significativo apenas a partir do extrato B1. Os extratos menos valorizados (B3, B4, B5 e C) agrupam o maior percentual de periódicos editados em língua não inglesa e a presença de periódicos em inglês é praticamente nula nesses extratos. Mas por que esse fenômeno ocorre? Será que tudo o que é escrito em inglês possui qualidade superior ao que é escrito nas línguas nativas? Por que nossa língua tem menos valor em nossa própria terra?

O estudo realizado por Machado-da-Silva e outros (2008) sobre o FI dos periódicos brasileiros nos revela que, entre os periódicos brasileiros de gestão e organização, a melhor avaliação foi para a Revista de Administração de Empresas (RAE), com 39,78\% das citações, seguida da Revista de Administração Contemporânea (RAC), com 15,70\%, Revista de Administração da USP, com 13,16\% e RAP, com 10,65\% do total de citações. O periódico $B A R$ aparece na $11^{\underline{a}}$ posição, com $0,8 \%$ das citações. Ora, mas por que este periódico, com menos de 1\% das citações, compõe o extrato A2 do novo Qualis? Seria porque, como os autores afirmam, trata-se do "[...] primeiro periódico de administração no país com foco e amplitude internacional" (MACHADO-DA-SILVA e outros, 2008, p.

\section{Gráfico 1 - Distribuição percentual dos periódicos de acordo com o sistema de avaliação Qualis}

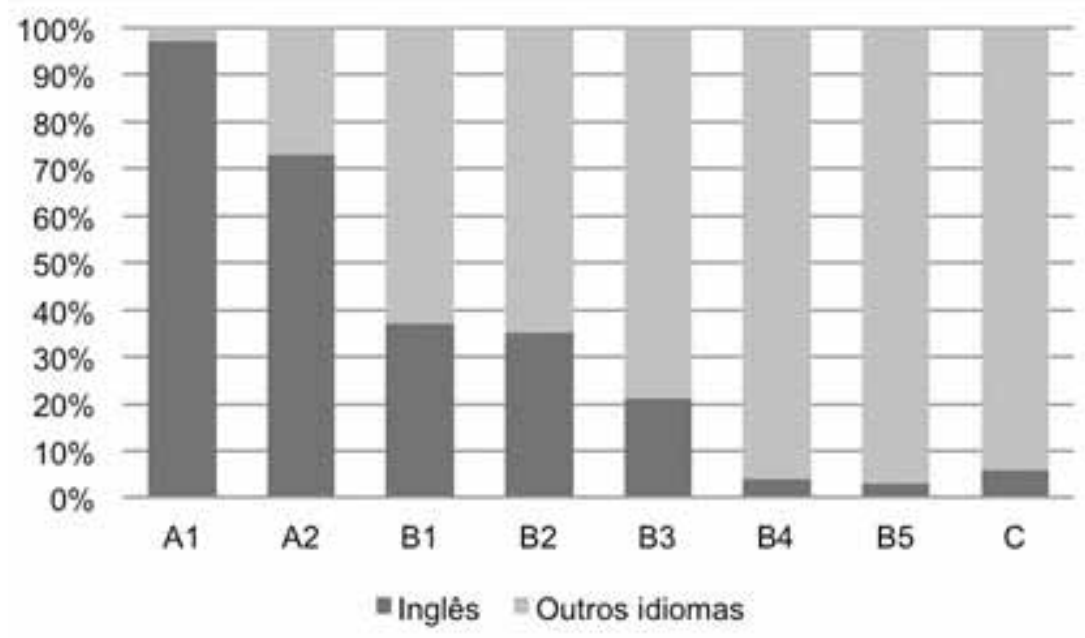


365)? O que estes autores querem dizer com "foco e amplitude internacional"? O impacto dele na pesquisa internacional ou o fato de ser um periódico brasileiro na área editado totalmente no idioma inglês? Deixamos esta resposta para pesquisas futuras... O que nos interessa aqui é o fato de um periódico brasileiro pouco citado e editado em língua inglesa fornecer maior pontuação que os demais, tornando-se mais atrativo na hora de submeter um artigo e, ainda, ser visto como o "primeiro" a ter foco e amplitude internacional pelo fato de ser editado em inglês.

Utilizar o FI como instrumento de medida e avaliação, apurado pelo Institute for Scientific Information (ISI), através do Journal Citation Report (JCR), implica nos inserirmos num contexto transnacional de valorização científica que coloca nossa produção em competição direta com a produção mundial, cujo controle está nas mãos do Norte Global. Apenas como exemplo, Targino e Garcia (2000) destacam que, dos 17 periódicos brasileiros indexados pelo ISI, apenas dois deles $(11,77 \%)$ são editados em português: a $D a$ dos - Revista de Ciências Sociais e a Revista Brasileira de Zootecnia. Todos os demais são editados em inglês. Isto é, se o FI se constitui a partir da repercussão de um periódico na construção do conhecimento científico, que é mensurado a partir do número de citações desse periódico, então, para que um periódico brasileiro obtenha altos índices de citação, isso implica que ele seja editado em inglês? Como ficam os periódicos brasileiros num contexto anglófono em que, mesmo no nosso próprio contexto linguístico, ainda somos menos citados do que eles? Qual é o futuro dos periódicos brasileiros nesse contexto?

Conforme ressalta March (2004), os periódicos mais importantes da área de gestão e organização são os norte-americanos Academy of Management Journal, Academy of Management Review, Administrative Science Quarterly e Organization Science e os europeus de língua inglesa Journal of Management Studies, Organization, Organization Studies e Scandinavian Journal of Management, cujo impacto se dá pela repercussão que causam na área. Colocar os periódicos brasileiros na mesma base de indexação desses periódicos implica uma extinção anunciada dos nossos periódicos, na medida em que estariam tão desvalorizados que o fluxo de publicações brasileiras seria canalizado para estes periódicos em virtude de sua maior valorização no campo. A consequência disso seria a consolidação do idioma inglês como "língua franca", pois todos eles são editados nesse idioma.
Desse modo, para obter maiores pontuações, os pesquisadores brasileiros devem publicar suas pesquisas nos periódicos indicados por March (2004), o que implica se submeter à lógica de pensamento e redação anglófonos e, principalmente, ser fluentes no idioma inglês, tanto na forma falada (por conta dos encontros e eventos científicos internacionais) como na forma escrita (em função dos periódicos mais bem classificados). Dentro desse contexto, não possuir essas habilidades resulta em não ter voz no campo.

\section{PODE $O$ CGO FALAR PORTUGUÊS?}

Ao analisar a situação da América Latina no contexto internacional de produção acadêmica na área de gestão e organização, Ibarra-Colado (2006) identifica a presença de um conjunto de mecanismos que se colocam como um tipo de "colonialidade epistêmica", que busca, sobretudo, marginalizar o conhecimento produzido na região, encerrando-o numa posição de "subalternidade". Diante de tais mecanismos, restaria ao pesquisador subalterno resistir por meio de um processo de "descolonização" ou se sujeitarem às regras impostas pelos países anglófonos, pois "para pertencer à 'comunidade internacional', você deve falar a língua do Centro, usar seus conceitos, discutir suas agendas e estar em conformidade com o estereótipo do 'sul imperfeito', mantendo um 'silêncio educado' sobre as causas reais de seus problemas" (IBARRACOLADO, 2006, p. 471).

Considerando que o campo acadêmico é um espaço onde os agentes disputam posições próximas ao centro das decisões definidoras da pesquisa, da publicação e do ensino na área, então a proposição de Ibarra-Colado (2006) é verdadeira na medida em que somente os agentes que optam por fazer parte da "comunidade" se dispõem a assumir a linguagem do Centro para acumular prestígio no campo e usufruir dos benefícios materiais e simbólicos dessa posição. Ao fazer isso, porém, ele irá disputá-los com outros agentes que ocupam posições privilegiadas neste campo, pois foram formados nele e, por isso, possuem maiores chances de desempenharem eficientemente esta linguagem. Desse modo, se a linguagem do campo é "representada" pelo idioma inglês, então a condição de subalterno ou de dominante dependerá do domínio que se tenha desse idioma. Isso determinará as possibilidades de estar no "centro" ou na "periferia" do campo acadêmico, conforme ilustra a Figura 1. 
No centro, estão os agentes mais habilitados a seguir a lógica do campo e a ocupar os espaços de poder no centro do campo. Trata-se dos "nativos da língua inglesa", cuja formação intelectual se deu toda em contexto anglófono, o que os habilita a transitar no campo acadêmico sem qualquer restrição e sem a necessidade de ser traduzido ou representado. Esse sujeito tem acesso irrestrito a todo o conhecimento "de qualidade" que circula no campo, além de poder expressar-se de maneira natural em todas as suas comunicações dentro do campo, seja por meio verbal (aulas, palestras e debates), seja por meio escrito (artigos, livros e projetos). A produção científica dos nativos de língua inglesa tem maior valorização, na medida em que corresponde ao modo de ver, sentir e pensar anglo-saxão, que é exigido nos principais espaços de divulgação científica internacional. No primeiro espaço periférico, diretamente ligado ao centro, estão os falantes de "inglês como segunda língua" (indianos, sul-africanos, filipinos etc.), que desfrutam das mesmas possibilidades dos nativos, porém com algumas restrições quanto ao sotaque e às variações que o inglês sofre ao conviver na sombra de outro idioma.

No segundo espaço periférico, mais distante do centro, estão os sujeitos que não foram formados no contexto anglófono, mas que dominam o "inglês como língua estrangeira". Para esse sujeito, as restrições são maiores, pois variam de acordo com o investimento feito no aprendizado do idioma. Aqui temos identidades que podem variar do "comprador" ao "quase subalterno". O "comprador", conforme já discutimos, é aquele membro da elite local que teve acesso aos códigos do centro, por isso consegue ser um bom mediador com a periferia do campo, consegue traduzir alguns destes códigos, mas nem todos. Trata-se dos "adolescentes promissores" descritos por Ibarra-Colado (2006), como aqueles sujeitos que foram mandados para os EUA ou Europa por governos e universidades para adquirirem o "know how" de como se expressar em inglês e publicar em revistas localizadas no Centro. Ao retornarem "[...] sua missão é espalhar essa 'nova cultura' entre os seus colegas em um ato de renovação da colonização interna" (p. 471). Já o "quase subalterno" é aquele sujeito que, diferente do comprador, acessou os códigos do centro em sua própria localidade e, por isso, possui maiores limitações que aquele, mas sobrevive a partir de parcerias com grupos mais próximos do centro, com quem compartilha publicações e projetos como parte da sua atividade científica que é também voltada para as revistas existentes no País (RUSSEL, 1998).

Na margem do campo, praticamente fora dele, estão os sujeitos que não foram formados no contexto anglófono e que também "não têm proficiência no inglês". Trata-se do sujeito "subalterno" que, segundo Spivak (1988), não possui o direito de falar sem ser representado, pois, como não possui os códigos do centro, sua enunciação depende de intermediários, intérpretes que são, na maioria das vezes, incapazes de traduzir toda a carga simbólica atrelada ao discurso subalterno, enunciando o que lhe convém. No contexto da hegemonia do inglês, o subalterno - que fala apenas o português - está praticamente excluído do campo, pois não tem

\section{Figura 1 - Centro e periferia no campo acadêmico transnacional} segundo a proficiência no idioma inglês

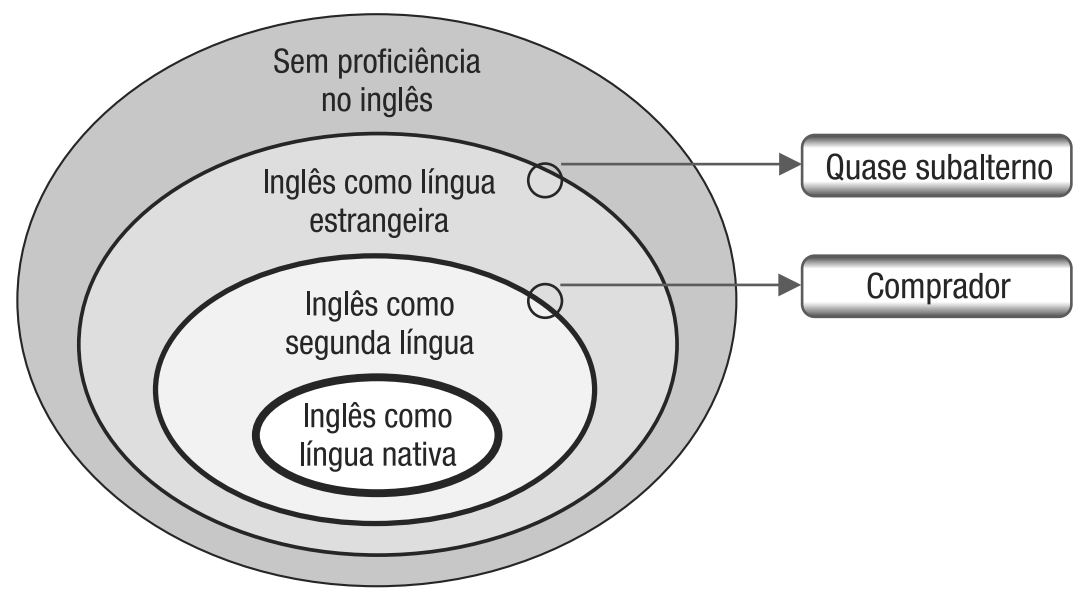


o direito de falar. Silenciado, está preso na periferia do campo e "condenado" a reproduzir didaticamente o conhecimento que é produzido no centro.

Como observam Laclau e Mouffe (2001), todavia, uma propriedade inerente aos processos hegemônicos é o seu caráter "precário" e "contingente". O que significa que esta hegemonia do inglês no campo acadêmico não é definitiva e pode ser alterada a qualquer momento. Nesse sentido, uma contra-hegemonia pode ser articulada pelos sujeitos subalternos com os demais sujeitos periféricos, a começar pelos "quase subalternos", seguidos do "comprador", conforme apresentamos no próximo item das considerações finais.

\section{CONSIDERAÇÕES FINAIS}

Nosso objetivo neste trabalho foi o de questionar se o CGO poderia falar um idioma diferente do inglês. Para tanto, iniciamos nossa discussão com uma breve descrição do papel do idioma inglês no mundo globalizado e a sua crescente presença na comunicação científica, sendo visto por alguns defensores deste processo como a "língua franca" da ciência. No contraponto desse argumento, desenvolvemos uma postura crítica quanto ao uso funcional do inglês na comunicação científica, pois não se trata de um processo neutro, ao contrário disso, trata-se de poderoso mecanismo que visa reproduzir uma lógica colonial em que o Norte Global define os parâmetros de produção, circulação e disseminação do CGO no contexto transnacional, excluindo dessa dinâmica os conhecimentos produzidos no Sul Global, que, por estarem fora dos códigos anglofônicos, são encerrados na posição "subalterna".

Sem a pretensão de resolver a questão neste pequeno ensaio, mas sim de abrir essa discussão no campo, pensamos que o equilíbrio nas relações acadêmicas entre o Norte e o Sul depende de uma valorização do CGO produzido no Sul, o que implica um movimento de contra-hegemonia organizado pelos próprios sujeitos subalternos. Como esses sujeitos não foram formados no centro, possuem um grau de conformidade menor com a lógica hegemônica, o que facilita a ruptura e ajuda a pensar, de maneira menos colonizada, as possíveis mudanças a serem feitas na estrutura do campo acadêmico. A começar pela desconstrução do que hoje se entende por "internacional", seguida de uma revisão crítica dos parâmetros de avaliação da produção científica, vista neste contexto como principal elemento de valorização e legitimação da língua inglesa como "língua franca".

O sucesso deste movimento vai depender de uma mudança nas regras de circulação e avaliação da produção científica ${ }^{1}$. Isso implica uma resistência comprometida com a "descolonização", com a possibilidade de olhar nossa própria forma de narrar a gestão e as organizações brasileiras, a partir de nossos próprios recursos linguísticos e nossas próprias capacidades de falar e escrever sobre nós mesmos. Não se trata de propor aqui um tipo de isolamento ou movimento contra a anglofonia, mas de resgatar a proposta de Fernando Pessoa, de nos comprometermos com a língua nativa, tendo-a como nossa própria pátria, a qual temos o dever de preservar e de defender.

\section{REFERÊNCIAS}

APPADURAI, A. Sovereignty without territoriality: notes for a postnational geography. In: YAEGER, P. (Ed) The geography of identity. Michigan: U. of Michigan Press, 1996.

ASHCROFT, B; GRIFFITHS, G; TIFFIN, H. The postcolonial studies: the key concepts. 2nd ed. London: Routledge, 2000.

BERTERO, C; KEINERT, T. A evolução da análise organizacional no Brasil (1961-93). RAE-Revista de Administração de Empresas, v. 34, n. 3, p. 81-90, 1994.

BERTERO, C; CALDAS, M; WOOD JR, T. Produção científica em administração no Brasil: o estado-da-arte. São Paulo: Atlas, 2005.

BOURDIEU, P; WACQUANT, L. On the cunning of imperialist reason. Theory, culture and society, v. 16, n. 1, p. 41-58, 1999.

\section{NOTA}

Uma experiência de resistência interessante vem da Sociedade Brasileira de Sociologia. 0 comitê da área de Sociologia da CAPES, fortemente influenciado por esta sociedade científica, fez um vigoroso movimento para forçar o reconhecimento da qualidade internacional de certos periódicos em Português, criando uma definição endógena de internacionalização (DWYER, 2010). 
BOYACIGILLER, N; ADLER, N. The parochial dinosaur: organizational science in a global context. Academy of Management Review, v. 16, n. 2, p. 262-290, 1991.

CRYSTAL, D. English as a global language. Cambridge: University Press, 1997.

DE SWAAN, A. The evolving European language system: a theory of communication potential and language competition. International political science review, v. 14, n. 3 , p. 241-255, 1993.

DUSSEL, E. Eurocentrism and modernity. Boundary 2, v. 20, n. 3, p. 65-76, 1993.

DWYER, Tom . On the Internationalization of Brazilian Academic Sociology. In: BURAWOY, M.; CHANG, M.; HSIEH, M. F. (Org.). Fancing an Unequal World: Challenges for a Global Sociology. Taipei: Institute of Sociology, Academia Sinica Council of National Associations of the International Sociol, 2010, pp. 84-104.

ESCOBAR, A. Worlds and knowledge otherwise: the Latin American modernity/coloniality research program. Cultural studies, v. 21, n. 2-3, p. 179-203, 2007.

FANON, F. The wretched of the Earth. New York: Grove Press, 1965.

FAUSTO, B. História do Brasil. São Paulo: Edusp, 1995.

FRENKEL, M; SHENHAV, Y. From Americanization to colonization: the diffusion of productivity models revisited. Organization studies, v. 24, n. 9, p. 1537-1561, 2003.

GOULART, S; CARVALHO, C. O Braziltá matando o Brasil. Revista de Administração Contemporânea, v. 12, n. 3, p. 873-881, 2008.

HAMEL, R. The dominance of English in the international scientific periodical literature and the future of language use in science. AILA Review, v. 20, p. 53-71, 2007.

IBARRA-COLADO, E. Organization studies and epistemic coloniality in Latin America: thinking otherness from margins. Organization, v. 13, n. 4, p. 463-488, 2006.

KUSHNER, E. English as global language: problems, dangers, opportunities. Diogenes, v. 59, n. 2, p. 17-23, 2003.

LACLAU, E; MOUFFE, C. Hegemony and socialist strategy: towards a radical democratic politics. 2nd ed. London: Verso, 2001.

LUIZ, R. Avaliação de produtividade acadêmica: uma proposta de quantificação. Revista Brasileira de Pós-Graduaç̧ão, v. 3, p. 6, p. 300-312, 2006.

MACHADO-DA-SILVA, C. e outros. Periódicos brasileiros de Administração: análise bibliométrica de impacto no triênio 2005-2007. RAC-Eletrônica, v. 2, n. 3, p. 351-373, 2008.

MARCH, J. Parochialism in the evolution of a research community: the case of organization studies. Management and Organization Review, v. 1, n. 1, p. 5-22, 2004.

MERILÄINEN, S. e outros. Hegemonic academic practices: experiences of publishing from periphery. Organization, v. 15, n. 4, p. 584-97, 2008.

MIGNOLO, W. The geopolitics of knowledge and colonial difference. The South Atlantic Quarterly, v. 1, p. 57-96, 2002.

ORTIZ, R. As ciências sociais e o inglês. Revista Brasileira de Ciências Sociais, v. 19, p. 5-22, 2004.

PEASE, D. US imperialism: global dominance without colonies. In: SCHWARZ, H; RAY, S. (Ed) A companion to postcolonial studies. Oxford: Blackwell Publishing, 2005.

PHILIPSON, R. Linguistic imperialism. London: Oxford University Press, 1992.

PROCHNO, P. A sociologia é um esporte de combate: uma réplica ao texto de Sueli e Cristina. Revista de Administração Contemporânea, v. 12, n. 3, p. 855-860, 2008.

QUIJANO, A. Coloniality of power, ethnocentrism and Latin America. Nepantla, v. 1, n. 3, p. 553-580, 2000.

RAMA, A. A cidade das letras. São Paulo: Brasiliense, 1985.

RODRIGUES, S; CARRIERI, A. A tradição anglosaxônica em estudos organizacionais brasileiros. Revista de Administração Contemporânea, v. 5 (Ed. Especial), p. 81-102, 2001.

RUSSEL, J. Publishing patterns of Mexican scientists: difference between national and international papers. Scientometrics, v. 41, n. 1, p. 113-124, 1998.

SANTOS, B. S. Toward a new common sense: law, science and politics in the paradigm transition. New York: Routledge, 1995.

SANTOS, B. S. Para além do pensamento abissal: das linhas globais a uma ecologia de saberes. Revista Crítica de Ciências Sociais, v. 78, p. 3-46, 2007.

SPIVAK, G. Can the subaltern speaks? In: NELSON, C; GROSSBERG, L. (Ed) Marxism and the interpretation of culture. Illinois: University Press, 1988.

TARGINO, M; GARCIA, J. Ciência brasileira na base de dados do Institute for Scientific Information (ISI). Ciência da Informação, v. 29, n. 1, p. 103-117, 2000.

THOMAZ, O. Tigres de papel: Gilberto Freyre, Portugal e os países africanos de língua oficial portuguesa. In: BASTOS, C; ALMEIDA, M; FELDMAN-BIANCO. B. (Ed) Trânsitos coloniais: diálogos críticos luso-brasileiros. Campinas: Unicamp, 2007.

TIKLY, L. Education and the new imperialism. Comparative education, v. 40, n. 2, p. 173-98, 2004.

VERGARA, S. A hegemonia americana em estudos organizacionais. Revista Brasileira de Administração Pública, v. 35, n. 1, p. 63-77, 2001.

VERGARA, S; PINTO, M. Referências teóricas em análise organizacional: um estudo das nacionalidades dos autores referenciados na literatura brasileira. Revista de Administração Contemporânea, v. 5, n. 2, p. 103-121, 2001. 